\title{
El ascendiente de Thomson y Saint-Lambert en los romances rurales de Meléndez Valdés
}

\author{
(Thomson and Saint-Lambert as Sources \\ of Meléndez Valdés's Rural Poetry)
}

\author{
Ángeles García CALDERÓN \\ Universidad de Córdoba
}

\begin{abstract}
Fecha de recepción: 14 de febrero de 2011
Fecha de aceptación: 14 de marzo de 2011
\end{abstract}

Resumen: Trabajo que trata sobre la influencia tradicionalmente mencionada por la crítica y estudiosos del poeta extremeño de algunos autores extranjeros en la poesía moral y filosófica, sobre todo en los romances y en concreto de James Thomson y su imitador francés Saint-Lambert. Tras una introducción al tipo de poesía que va a triunfar en Europa en el siglo XVIII, formado por la asociación del tema de la naturaleza y el novedoso concepto de sensibilidad impuesto por Rousseau en Julie ou la Nouvelle Héloïse, se lleva a cabo un breve análisis de la situación de la poesía descriptiva de la naturaleza en Inglaterra anterior a Thomson y la importancia de su poema The Seasons, que será traducido, imitado y adaptado en Europa y del cual se transcribe el texto en el que basarán Saint-Lambert y luego el propio Meléndez. Una segunda parte disecciona la adaptación francesa de Saint-Lambert, que ya en el prólogo pone de relieve tanto la intención de su imitación como aquello que lo separa de su modelo. Finalmente, un breve análisis del poema "Las vendimias" (que consta de 208 octosílabos), muestra la escasa influencia del original y su imitador francés, a no ser en el tema elegido, que Meléndez utiliza para describir las costumbres de los vendimiadores extremeños.

Palabras clave: Poesía descriptiva. Traducción. Imitación. Thomson. Saint-Lambert. Meléndez Valdés.

Abstract: This paper attempts to discuss the influence, often remarked by scholarly critics, of several foreign poets and moral philosophers on the poet from Extremadura and more specifically on the ideas Meléndez Valdés drew from Thomson and his French imitator, Saint-Lambert. The paper starts with a brief introduction to the type of poetry that would be successful in Europe the oncoming $18^{\text {th }}$ century, which linked together the topic of Nature and the novel concept of sensibility put forward by Rousseau in Julie ou la nouvelle Heloise, which is followed by an insight into the panorama of the descriptive poetry in England before Thomson, and an assessment of Thomson's The Seasons, often translated, imitated and adapted in Europe I offer here the passages of the poem wherefrom Saint-Lambert and then Meléndez Valdés drew their work. This is followed by Saint-Lambert's own adaptation which is discussed at some length, where the author recognizes his imitative intention as well as the difference with his sources. Finally, I offer a brief analysis of the poem "Las vendimias" (208 octosyllabic lines) where a scarce 
influence, except for the topic, can be traced of the original source and its French imitator. There Meléndez Valdés draws on the local customs of the people from Extremadura when they go out to collect the vineyards harvest.

Key words: Descriptive Poetry. Translation. Imitation. Thomson. Saint-Lambert. Meléndez Valdés.

\section{INTRODUCCIÓN}

El siglo XVIII literario, tan denostado en algunos países europeos en lo que se refiere a la poesía, paradójicamente va a posibilitar un cambio fundamental en este género debido fundamentalmente a la asociación de dos conceptos que hasta entonces no habían generalmente confluido en el poema: el tema de la naturaleza y la sensibilidad. Juntos van a dan lugar a un tipo de poesía muy concreto que, extendiendo sus raíces desde Inglaterra, Alemania y Francia van a irradiar a toda Europa con un patrón de obras similares cuya vigencia va a prefigurar buena parte de los motivos literarios de la propia estética del Romanticismo.

El primero de los dos conceptos, la poesía de la naturaleza, denominación que permite englobar los poemas pastoriles, bucólicos, geórgicos, anacreónticas, églogas, idilios, etc. adquiere en el siglo XVIII un carácter descriptivo y de reflexión filosófica ${ }^{1}$, atreviéndose el escritor a propugnar un elogio de la unión entre la poesía y la filosofía. De este modo, se va a imponer un tipo de poesía descriptiva en el que ciertos escritores de lengua inglesa (James Thomson y John Philips) y de lengua alemana (Haller, el autor de Alpes -1729- y el pintor y poeta Salomon Gessner ${ }^{2}$ ) tienen una importancia primordial en el desarrollo del género. De los cuatro autores citados no hay duda de que el más importante para el tema que nos ocupa es el escocés James Thomson, cuya obra The Seasons aparecerá en 1730, aunque ya la primera de sus cuatro estaciones, Winter, viera la luz cuatro años antes. Se trata de una transformación del sentimiento de la naturaleza con dos líneas muy bien definidas: la representación de la naturaleza artificiosa que describe los deleites del campo y que se plasma en el género pastoril y en églogas a imitación de Virgilio y Spencer, y otra variante más rica siguiendo la estela de Las Geórgicas, que se nutre de poemas descriptivos y meditativos.

\footnotetext{
${ }^{1}$ Es preciso distinguir el poema didáctico, que transmite una enseñanza o un mensaje (es el caso de De Natura Rerum de Lucrecio), del poema descriptivo, sin modelo en la Antigüedad y que, heredero del enciclopedismo del Siglo de las Luces, presenta las diferentes facetas de la Naturaleza o la multiplicidad de los conocimientos.

${ }^{2}$ Para la influencia de Gessner en concreto véase el artículo de García Calderón, A.: "Salomon Gessner y su influencia en Meléndez Valdés a través de Thomson", Futhark 2, Sevilla, Editorial Bienza, 2007, pp. 131-147.
} 
La introducción de la "estética de la sensibilidad" en el poema hay que achacársela casi por completo al nuevo modo de entender, contemplar y participar de la naturaleza que plasma Rousseau en su Julie ou la Nouvelle Héloïse (1761); en efecto, no se había visto hasta ese momento esa imbricación entre personajes y Naturaleza (que adquiere la categoría de otro personaje más), en la que los estados de aquéllos se ven condicionados por el momento del día y por la "expresión" o cara que ésta muestre ${ }^{3}$.

Según estas premisas la segunda mitad del siglo ya desvela un nuevo horizonte, influenciado en gran medida por la moda inglesa, el "idilismo" alemán y la nueva sensibilidad puesta de relieve por Rousseau en su novela epistolar, influencias todas que va a recoger Meléndez Valdés en sus romances "más filosóficos" y en sus Odas filosóficas y sagradas. Por lo que respecta a Thomson, Meléndez leerá al poeta escocés en el original inglés ${ }^{4}$, y el poema ejercerá bastante influencia sobre algunas composiciones del extremeño. En cuanto a Saint-Lambert, en la conocida correspondencia con su amigo Jovellanos el poeta extremeño le comenta en 1778:

Delio está leyendo el poema las Estaciones de Saint-Lambert, que yo he traído de Segovia; a mí me ha gustado mucho. Hace en las notas y el prólogo una mención muy honrosa de Thomson, y aún toma algunos versos suyos; pero en el plan de la obra son muy diferentes entre sí; el prólogo, que es un discurso sobre las poesías y estilo pastoril me ha agradado también; en él alaba mucho las poesías de Gessner como las más sencillas de todas las modernas. Yo no he visto nada de él, por lo que, si V. S. tiene algunas noticias más circunstanciales, o ha visto acaso sus églogas, estimaré mucho me diga su parecer y si juzga de ellas tan ventajosamente como el autor de las Cuatro Estaciones.

Ya Emilio Palacios Fernández en su "Estudio preliminar de las poesías de Juan Meléndez Valdés" ${ }^{5}$ destacó en su momento la influencia del escocés y el francés sobre el poeta extremeño:

\footnotetext{
${ }^{3}$ Destaquemos en este punto la figura del místico de Silesia Jacob Böhme (1575-1624) de cuya obra, De Signatura Rerum (1621), se publica en Inglaterra una traducción en 1651. Según Böhme, todo lo que existe tiene una correspondencia o un comercio secreto con el mundo invisible; así, el mundo exterior es un reflejo del mundo interior y espiritual; en la medida en que Dios se manifiesta en la naturaleza el paisaje adquiere una importancia creciente en la poesía: la naturaleza se convierte en un paraíso terrestre en el que el poeta se refugia y experimenta un placer casi sensual, que se transforma pronto en éxtasis místico.

${ }^{4}$ En su biblioteca constaba un ejemplar de Seasons, edición de 1744.

${ }^{5}$ Meléndez Valdés, Juan, Poesías, Edición, estudio y notas de Emilio Palacios Fernández, Madrid, Alhambra, 1979.
} 
Tres «romances cultos» encierran la clara preocupación de Meléndez por el mundo rural. Los tres unen elementos descriptivos de la naturaleza con valor temporal, relacionados, por lo tanto, con otros poemas del mismo tipo y el interés humano. "Los segadores» es el primero de ellos. Menos crítico, adopta una actitud entre paternalista y providencialista, para acabar en una ascensión casi espiritualistacaritativa. Es una invitación alegre a la siega, mientras Meléndez maneja los tópicos usuales de la inocencia campestre, la alegría del trabajo,... El poema guarda en sus aspectos descriptivos cierta influencia de Saint Lambert y Thomson. El romance XXXV, «Los aradores", está escrito en el mismo tono e ingredientes. Visión del campo y labores rurales de invierno, descritas con belleza y precisión. El análisis se completa con un bosquejo gozoso de la familia campesina. Destaca sus virtudes de honradez, sobriedad y libertad frente a los vicios contrarios del hombre ciudadano... Esta pequeña trilogía de los oficios campesinos se cierra con el romance XXXVIII, «La vendimia». Idéntico espíritu y apropiadas descripciones temporales...

Efectivamente Meléndez no es ajeno a ninguna influencia del extranjero, sino todo lo contrario: el tema de la naturaleza y la estética de la sensibilidad toma cuerpo en un alma tan permeable, afectiva y delicada como la suya, desarrollándose en algunos de sus romances de un modo verdaderamente epidémico, sobre todo en aquellos que se refieren a las labores del campo o en los que describen los fenómenos climáticos de las estaciones, que llevan al escritor a la alegría o a la tristeza en sus diversos aspectos (melancolía, taciturnidad, tristeza, etc.) ${ }^{6}$. Veamos cómo se gesta esa poesía en Inglaterra y Francia.

\section{LA POESÍA DESCRIPTIVA DE LA NATURALEZA EN INGLATERRA ANTERIOR A THOMSON \\ Por lo que concierne a la situación específica de la poesía de la Naturaleza en Inglaterra, la pastoral es un género que se desarrolla en los siglos XVI y XVII y con prolongaciones en el XVIII. En particular, el paisaje tradicional de la pastoral atrae a numerosos poetas entre los predecesores}

\footnotetext{
${ }^{6}$ De ahí que tuviera en tanta estima la epístola de Pope Eloisa to Abelard, así como la versión que de ella llevó a cabo Colardeau. Además de estas dos notables influencias en la poesía de Meléndez, otra hipotética pudo acontecer; me refiero a la proveniente de la traducción que del poeta escocés llevó a cabo el plesbítero Benito Gómez Romero, publicada en dos tomos en 1801: Thomson, James: Las estaciones del año, poema de Jayme Thompson [sic], traducido por D. Benito Gómez Romero, presbítero, Madrid, Imprenta Real, 1801, 2 vols. Aunque en la edición de 1797 ya están incluidos la mayor parte de los romances, no es descabellado suponer que el autor conociera gran parte de la obra de Gómez Romero, que debió redactarla en la última década del XVIII.
} 
de Thomson. Sir Philip Sidney fija sus normas en un pasaje, ya célebre, de Arcadia, relato pastoril entremezclado de verso, escrito en 1580-1581 y publicado en 1590:

There were hills which garnished their proud heights with stately trees: humble vallies, whose base estate seemed comforted with refreshing of silver rivers: meadows, enameld with all sorts of ey-pleasing floures: thickets which being lined with most pleasant shade, were witnessed so to by the cheerful deposition of many wel-tuned birds: each pasture stored with sheep feding with sober security, While the pretty lambs with bleting oratory craved the dams comfort...?

Este paisaje idílico no es cerrado, aunque da la impresión de ser un enclave en la vida normal. De hecho, está protegido por un cinturón de colinas coronadas de árboles majestuosos que prohíben el acceso a ellas. En el propio corazón de este retiro reina una cierta diversidad, gracias a los valles surcados por riachuelos, a las praderas recubiertas de flores multicolores y a los bosques umbríos. El silencio, que termina por engendrar la melancolía o la monotonía, es roto por el canto alegre de los pájaros. Las casas, dispersadas, permiten a los habitantes de esta comarca encantada saborear a la vez el trato con sus semejantes y los placeres de la soledad, lejos del ruido y del mundo.

Spencer nos proporciona, en su The Shepheard's Calendar (1579), una mezcla asombrosa de idealismo y de realismo: el poema evoca el mundo idealizado de la pastoral clásica, describiendo a pastores ingleses de la época y sugiriendo el universo interior del poeta, en el que reina la imaginación con total libertad. Pope y Ambrose Philips se inspirarán de la atmósfera general del poema, que no presenta descripciones detalladas de paisajes. The Faerie Queene, cuyos tres primeros libros son publicados en 1590, es más interesante a ese respecto; el 'Bosque de las Delicias' (Libro II, Canto XII), en el que Guyon (el caballero de la templanza) ve lomas, riachuelos, colinas, vallecillos y una profusión increíble de flores, revela la riqueza de la Naturaleza que se muestra en todo su esplendor, aunque Spencer no olvide que estas bellezas naturales disimulan la artificiosidad y sólo son ilusorias. Por el contrario, el 'Jardín de Adonis' (Libro III, Canto VI), es un verdadero paraíso en el que la primavera es eterna, donde la abundancia y los placeres manan a borbotones. En él, la Naturaleza da una impresión de exuberancia, de plenitud, que anuncia la descripción del Edén en el Libro IV de Paradise Lost.

La pastoral nos muestra una perspectiva de vida simple y armoniosa, donde la amistad y el amor se expanden sin sujeción, sin tener que sufrir las

${ }^{7}$ Citado por John Heath-Stubbs en The Pastoral, Oxford University Press, 1969, p. 27. 
presiones impuestas por la vida corriente. El odio y la cólera dejan de tener sentido al contacto de esta armonía que existe entre los seres, gracias al decorado natural que hechiza los sentidos, aparta las dificultades y suprime el trabajo y la competencia. El mundo encantado de la pastoral aporta el apaciguamiento y una quietud que no turba preocupación alguna. Esa es la tranquilidad que se percibe en un encantador poema 'elisabethiano' que recrea la Edad de Oro, utilizando el decorado y el lenguaje de la pastoral:

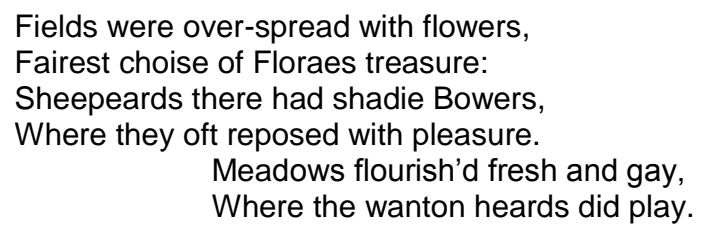

Hills with trees were richly dight,

Vallies stor'd with Vestaes wealth:

Both did harbour sweet delight,

Nought was there to hinder health.

Thus did heaven grace the soyle:

Not deform'd with work-mens toile. ${ }^{8}$

Michael Drayton (1563-1631) adorna sus églogas con elemento realista pronunciado que las distingue de la tradición spenceriana, uniéndose de este modo con la corriente realista y satírica de las pastorales de John Gay. William Browne (1591-1643), amigo de Drayton y de Ben Jonson, y discípulo de Sidney y Spencer, expresa en Britannia's Pastorals y The Shepherd's Pipe un amor sincero por la Naturaleza y un interés singular por el paisaje y las tradiciones de Devonshire, interés que recuerda el que John Philips manifestará más tarde en Cyder por los pastores de Herefordshire. Browne ejercerá una influencia lejana sobre Keats y los románticos. Las Piscatorie Eclogues de Phineas Fletcher (1580-1650), cuyos personajes son pescadores y no pastores, sugerirán quizás a William Diaper la idea de las Nereides (1712), pastoral marina que figura entre las obras más originales del siglo XVIII.

Sin embargo, en el siglo XVII son los libros IV y V de Paradise Lost los que John $\mathrm{R}$. Knott definirá como un "poema épico con un núcleo pastoril"," marcando con su huella la mayor parte de los poemas

${ }^{8}$ Poema extraído de England's Helicon, ed. Hugo MacDonald (Cambridge, Massachusset, 1962) pp. 33-34. Citado por John R. Knott, Jr.: Milton's Pastoral Vision (Chicago and London, University of Chicago Press, 1971), pp. 7-8.

${ }^{9}$ En la obra citada: Milton's Pastoral Vision, Chicago and London, University of Chicago Press, 1971. 
descriptivos en el alba del siglo XVIII. El Edén es una versión cristiana de la Arcadia, y todo contribuye a recordar la atmósfera ideal de la pastoral: la topografía del jardín con sus colinas, valles, bosques y rebaños; así como la armonía que reina entre Adán y Eva y los paisajes que los rodean, las correspondencias etéreas entre su estado de alma y la Naturaleza, el ritmo apacible de sus jornadas y la pureza de su amor. Y no es asombroso que, siguiendo a Milton, los escritores estén obsesionados por la Edad de Oro, de la que sienten una gran nostalgia. Este sentimiento tenaz y conmovedor por la belleza de un mundo desaparecido para siempre, aparece en la obra de poetas tan distintos como Sir Samuel Garth, Ambrose Philips, John Philips, Alexander Pope, William Diaper o James Thomson.

El Jardín del Edén es a la vez preciso e intemporal, familiar y mítico, en los confines del sueño y de la realidad; estimula la imaginación sin perturbar los sentidos de la mesura. El lector queda desde el comienzo sorprendido por la variedad y el carácter dinámico del paisaje que describe Milton en el Libro IV: presenta el Edén por medio de una serie de círculos concéntricos que nos acercan poco a poco al corazón del jardín, el Bosque Nupcial donde se llevan a cabo los ritos secretos de la unión de Adán y Eva; en el exterior, el Edén está protegido por una colina escarpada, cubierta por una vegetación densa y abrupta, que hace difícil el acercarse a ella; un bosque de cedros, de pinos, de abetos y de palmeras, un muro cubierto de verde y una fila de árboles maravillosos, cargados de frutos de una gran belleza ${ }^{10}$. Posteriormente, en el interior del propio jardín, se descubren alternativamente las colinas, los valles y las llanuras del Edén, los campos soleados y los bosques umbríos, las grutas y las cavernas llenas de vides... Milton proporciona una "vista panorámica" que no es en absoluto estática (como la de Spencer en el Bosque de las Delicias): el paisaje tiene tres dimensiones y el ángulo de visión cambia sin cesar. En esta obra la Naturaleza conoce una gran plenitud, una riqueza que recuerda sin cesar que la Creación es la obra de un Dios benévolo y generoso. En este Paraíso al abrigo del frío, de los vientos y de las tormentas, en el que reina una eterna primavera, Milton sugiere la atracción sensual del jardín en términos que sólo Keats llegará a igualar.

Un autor de gran popularidad a finales del siglo XVII y durante todo el XVIII, es el contemporáneo de Milton, Sir John Denham (1615-1669), debido a su poema Cooper's Hill (1642). A partir de 1713, el nombre de Denham no deja de asociarse al de Alexander Pope, que alude a su predecesor en Windsor Forest. Cooper's Hill es el primero de una larga línea de poemas "panorámicos" que son testimonio de la extensión de la visión. Los críticos del XVIII quedan sorprendidos por la mezcla de instrucción y de descripción

${ }^{10}$ Paradise Lost, ed. by H. Darbishire, Oxford, Clarendon Press, 1962. 
que lleva a la originalidad del poema, que se encuentra en la tradición de Las Geórgicas.

\section{1. "The Seasons" de James Thomson}

Tras esta breve revisión llegamos a Thomson y su obra ${ }^{11}$. La crítica se ha extendido en la idea de que a su llegada a Londres (1725) ya iba con una copia de Winter y la intención de redactar un poema didáctico religioso sobre la sublimidad de la Naturaleza. Tras el éxito de Winter (1726) Thomson compondrá el resto de las estaciones: Summer (1727), Spring (1728) y Autumn (1730) completando la obra en 1730 con el título general de The Seasons. La última edición revisada de todo el poema aparecerá en 1746; en ella la versión original de Winter, que constaba de 405 versos, es ampliada a 1269.

A la obra de Thomson se le ha concedido desde el momento de su publicación una gran importancia, tal vez debido al carácter excepcional de los temas que en ella se tratan. Llama la atención que no se centre en los mismos objetos que sus contemporáneos: el estudio del hombre, la reflexión ética y la sátira moralista, y ello puede que sea debido a que le atrajera mucho más el encanto natural de su región, que a finales de siglo despertaría el entusiasmo de la imaginación romántica de Walter Scott y de otros autores. Su mérito estriba en que supo tocar la fibra sensible de sus contemporáneos, mostrando las cualidades esenciales de su época que nadie antes que él había sabido plasmar con la misma intensidad y sensibilidad: si su talento se centró en la observación y delineación de la Naturaleza, su punto de vista fue totalmente contrario a las normas que marcaban la rebelión contra los límites impuestos por el siglo XVIII. Veamos, a continuación, el tratamiento que Thomson, su imitador SaintLambert y el propio Meléndez dan a las labores de vendimiar en un romance que éste último titula "Las vendimias". Thomson, al describir las labores del campo y los paisajes rurales transmite al lector la impresión de que el clima actúa en el contexto del cambio de estación, en especial las tormentas que acontecen en las cuatro estaciones, que son una especie de mecanismo de unión entre ellas. El pasaje en el que Thomson desarrolla las labores de la vendimia está incluido en su poema Autumn, versos $681-704^{12}$ :

\footnotetext{
${ }^{11}$ Cito la edición de 1772 (que forma parte de mi biblioteca) de la que mencionaré los versos de pasajes a los que aludo: James Thomson: The Seasons. To which is prefixed, An account of his Life and Writtings, London, Printed for A. Millar, MDCCLXII. La obra de Thomson se reeditó en numerosas ocasiones desde 1730. En internet podemos encontrar: The Seasons by James Thomson, with his Life, an Index and Glossary. A Dedication to the Earl of Bucham and Notes by Percibal Stockdale, London, Printed for A. Hamilton, 1793.

${ }^{12}$ Op. cit, p. 139.
} 
Turn we a moment Fancy's rapid flight

To vigorous soils, and climes of fair extent; Where, by the potent sun elated high,

The vineyard swells refulgent on the day;

Spreads o'er the vale; or up the mountain climbs,

Profuse; and drinks amid the sunny rocks,

From cliff to cliff increased, the heightened blaze.

Low bend the weighty boughs. The clusters clear,

Half thro' the foliage seen, or ardent flame

Or shine transparent; while perfection breathes

White o'er the turgent film the living dew.

As thus they brighten with exalted juice,

Touch'd into flavour by the mingling ray;

The rural youth and virgins o'er the field,

Each fond for each to cull the autumnal prime,

Exulting rove, and speak the vintage nigh.

Then comes the crushing swain; the country floats,

And foams unbounded with the mashy flood;

That, by degrees fermented, and refin'd,

Round the rais'd nations pours the cup of joy:

The claret smooth, red as the lip we press

In sparkling fancy while we drain the bowl;

The mellow-tasted burgundy; and quick,

As is the wit it gives, the gay champagne. ${ }^{13}$

\footnotetext{
${ }^{13}$ Para una mejor comprensión del texto, veamos su traducción: "Guiemos ahora al raudo vuelo de fantasía hacia fértiles suelos, y climas de amplias zonas, donde, debido al sol radiante allá en el cielo, crecen viñas ubérrimas con el fulgor del día; se extienden sobre el valle o trepan por los montes, en profusión; y beben entre soleadas rocas, desde un cantil al otro, el fuego crepitante. Con el peso las ramas se comban y el racimo, visible entre el follaje, flamea bien ardiente o transparente brilla; mientras raya el rocío la perfección tan blanca sobre turgente tela. Así las uvas lucen con su jugo, exultantes, con el sabor realzado por amistosos rayos; zagales y zagalas ociosos por el campo, con mutuo afecto cogen lo mejor del otoño, exultantes pasean y hablan de la cosecha. Llega luego el zagal que pisa; el campo flota, espumante sin límite con blanda inundación; el mosto fermentado lento y elaborado, brinda por las naciones con una alegre copa: el clarete tan suave, rojo como aquel labio que presionar soñamos al apurar la copa;
} 
En los 24 versos que el poeta escocés dedica a las labores de la vendimia, el lector parece encontrarse ante un texto que hubiese sido redactado más por un filósofo o un científico, que ha descubierto los trabajos secretos de la Naturaleza y se los transmite.

El poema de Thomson está redactado en el llamado "blank verse": verso libre y sin rima, como muchos de Shakespeare, aunque en el XVIII no sea lo común, que consiste en un metro de pie rítmico con cinco acentos (pentámetros yámbicos formados por sílaba no acentuada seguida de sílaba acentuada) de rima libre en estrofas también libres; como es frecuente hay alternancias con otros pies rítmicos, como el espondeo (pie rítmico con dos sílabas acentuadas seguidas) o troqueos y dáctilos (pie en el que se invierte la acentuación silábica: acentuada seguida de una o dos acentuadas respectivamente). Así, podemos hallar: 'spreads o'er the vale', un ritmo dactílico ya que el acento recae sobre la primera de las tres sílabas; igual ocurre en: 'touched into flavour'. En 'round the rais'd' hay un ritmo trocaico. Lo normal en el resto es el ritmo yámbico, como en la mayoría de las composiciones métricas en inglés. El sentido o contenido semántico se distribuye a lo largo de un número indeterminado de versos cuya cohesión y coherencia va desde los cuatro versos en los primeros cuatro del presente texto hasta un mínimo de dos versos (que es norma general).

En su poema el autor describe una natura viva, animada, palpitante, con capacidad naturante, natura naturans, que obra según su legitimidad, ofreciéndonos el modelo armónico del ser que vive en la tierra. El pasaje muestra casi una simetría perfecta: 13 versos para el objeto de descripción (la uva) y 11 para los que llevan a cabo los trabajos de recogida y elaboración ("The rural youth and virgins...").

\section{LES SAISONS DE JEAN-FRANÇOIS SAINT-LAMBERT}

En el siglo XVIII la poesía no es un gran género en el panorama literario poético francés: el mejor poeta de la centuria, André Chenier, escribe en la última década y en la primera mitad del siglo el género se nutre de poetas y poemas menores: "poésie légère o "fugitive" y composiciones de no mucha entidad (epigramas, epitafios, madrigales, fábulas...); buena prueba de ello es que sobresalga Voltaire, tan grande en otros géneros y tan poco reputado en éste. La segunda mitad ya desvela un nuevo horizonte, influenciado en gran medida por la moda inglesa, el "idilismo" alemán y la nueva sensibilidad puesta de relieve por Rousseau en su Nouvelle Héloïse. La moda inglesa, la que interesa a nuestro estudio, se

el añejo borgoña; el rápido champán,

como ese agudo ingenio que alegre nos otorga."

Hikma 10 (2011), 9-27 
plasma por medio de autores y obras muy concretas: Pope y su famosa epístola Eloisa to Abelard ${ }^{14}$, el escocés James Thomson que pondrá de moda en toda Europa los poemas descriptivos de la naturaleza ${ }^{15}$; finalmente Ossian y los poetas de la denominada "Graveyard Scholl", sobre todo Young y Gray.

El conocido como "chevalier" y luego "marquis" de Saint-Lambert (1716-1803), filósofo, poeta y diletante, llegó a ser considerado en su tiempo como un nuevo Virgilio, aunque la posteridad sólo conserve de él sus aventuras amorosas ${ }^{16}$; en 1769 publica una obra sobre la que llevaba trabajando bastantes años: Les Saisons, que gozará de un enorme éxito y le abrirá un año después la Academia. La obra fue reeditada numerosas veces en París, Londres ${ }^{17}$ y Ámsterdam. Para el duro crítico que era La Harpe el libro es la obra maestra del género descriptivo en Francia; Voltaire la considera "beau monument du siècle". En el bando contrario el inteligente y sutil Diderot pone de relieve que la obra "manque de verve et d'invention";

\footnotetext{
${ }^{14}$ Que dará lugar a las imitaciones francesas de Feutry (1751) y Colardeau (1758), que pone de moda el término "héroide" y hace que este tipo de composiciones se multipliquen. En España Colardeau será imitado por el vallisoletano Vicente María Santibáñez, Juan Maury y Castañeda, el abate Marchena y el propio Meléndez.

${ }^{15}$ Thomson es traducido por primera vez en prosa, en 1759 por Mme Bontemps, y luego en verso por Saint-Lambert (Les Saisons, 1769). Añadamos que la moda de la poesía descriptiva incluye también a Delille (Les Géorgiques, 1770 y Les Jardins, 1782), Roucher (Les Mois, 1779) y Lemierre (Les Fastes, 1779).

${ }^{16}$ Mme de Bouflers, Mme du Châtelet, Mme d'Houdetot..., su relación con la segunda, que muere a causa de un parto por sus amores con él, nos da pie para poner de relieve la generosidad intelectual y falta de rencor de un hombre como Voltaire: en su parto, mientras fallece la que había sido amante de Voltaire y era en ese momento de Saint-Lambert, aquél espetará a éste: "C'est vous qui me l'avez tué".

De vuelta en París, y cuando nadie parece ocuparse del poeta, que brilla más por sus escándalos que por su obra, Voltaire lo introducirá en los medios literarios demostrando una generosidad sin límites y una absoluta carencia de resentimiento.

7 Obra en mi poder un ejemplar de una edición de Londres de1782, sin nombre de autor ni casa de edición: Les Saisons, Poëme. Nouvelle édition. A Londres, M: DCC: LXXXII; de esta edición citaré.

Se ha afirmado con frecuencia que la mejor edición de la obra de Saint-Lambert es la de 1771; cito, a continuación, el resto de traducciones de Thomson más relevantes de la época:

-BONTEMPS, M. J. de Châtillon: Les Saisons, poème traduit de l'anglais de Thomson, Paris, 1759 (rééditions: 1761, 1779, 1788, 1795, etc.); primera traducción del autor escocés, en prosa. -DeLEUZE, J. F. P.: Les Saisons de Thomson, poème, traduction nouvelle, Paris, an X-1801.

-POULIN, J.: Les Saisons de Thomson traduites en vers français, Paris, 1802.

-ANONIME: Les Saisons, poème de Thomson, traduction nouvelle avec des notes par FreminBeaumont, Paris, 1806.

-ANONIME: Les Saisons imitées de Thomson, Orléans, 1818.

-MOULAS, Paul: Les Saisons, par Jacques Thomson, traduction en vers français, Lille, 1850

El mejor estudio sobre la influencia de Thomson en Francia sigue siendo el de Margareth C. Cameron: L'Influence des "Saisons" de Thomson sur la poésie descriptive en France (17591810), Paris, Honoré Champion, 1927.
} 
Mme du Deffand emite un juicio más severo: "Ce Saint-Lambert est un esprit froid, fade et faux... il est la stérilité même".

Parece ser que Saint-Lambert trabajó durante más de veinte años en su poema Les Saisons, obra totalmente descriptiva, sometida a unas reglas muy precisas de redacción y que no se puede afirmar que muestre la inspiración de su autor. El mayor mérito de sus versos es la elegancia, aunque eso no los libra de la monotonía y carencia de colorido y dan la impresión de describir cosas que desconoce y por la que no siente un gran amor, lo que se deja reflejar en su inspiración. Saint-Lambert es considerado como el imitador europeo más famoso de Thomson; en Les Saisons (1769), ya hacía notar que "Les anciens aimaient et chantaient la campagne, nous admirons et chantons la nature".

Veamos las estrofas, correspondientes a L'Automne, en las que Saint-Lambert imita el pasaje de Thomson:

Mais la feuille, en tombant du pampre dépouillé,

Découvre le raisin de rubis émaillé;

De l'ambre le plus pur la treille est colorée.

Les celliers sont ouverts, la cuve est réparée.

Boisson digne des dieux, jus brillant et vermeil,

Doux extrait de la sève, et des feux du soleil,

Source de nos plaisirs, délices de la terre,

Viens dissiper l'ennui qui me livre la guerre,

Et donne-moi du moins le bonheur d'un moment.

Bacchus, dieu des festins, père de l'enjoûment,

C'est toi qui répandis sur les monts du Bosphore

Les pampres enlevés aux portes de l'Aurore;

Tu couvris de raisins les rochers de Lesbos;

Ta liqueur inspira les muses, les héros,

Et ton culte polit la Grèce encor sauvage.

C'est toi qui des Gaulois enflammais le courage,

Quand ce peuple vainqueur, du haut des Apennins,

Vint sous leurs toits fumants écraser les Romains.

II voulait de tes dons enrichir sa patrie;

Et le front couronné des pampres d'Héspérie,

Ivre de vin, de joie, il repassa les monts.

Les vallons répétaient ses cris et ses chansons,

Et les thyrses guidaient sa marche triomphante.

La Gaule à ton nectar dut sa gaîté brillante,

Le charme des festins, et le sel des bons mots,

L'art d'écarter les soins et d'oublier les maux.

Mais déjà vers la vigne un grand peuple s'avance;

II s'y déploie en ordre, et le travail commence.

Le vieillard, que conduit l'espoir du vin nouveau,

Arrivé plein de joie au penchant du côteau, 
Y voit l'heureux Lindor et Lisette charmée

Trancher au même cep la grappe parfumée;

Ils chantent leurs amours, et le dieu des raisins.

Une troupe à leurs voix répond des monts voisins.

Et plus loin le tambour, le fifre et la trompette

Font entendre des airs que le vallon répète.

Fixent sur le côteau les regards du chasseur.

Mais le travail s'avance, et les grappes vermeilles

S'élevant en monceaux dans de vastes corbeilles,

Colin, le corps penché sur ses genoux tremblants,

De la vigne au cellier les transporte à pas lents;

Une foule d'enfants autour de lui s'empresse,

Et l'annonce de loin par des cris d'allégresse.

Tandis que le raisin sous la poutre est placé,

Qu'un jus brillant et pur dans la cuve est lancé,

Que d'avides buveurs y plongent la fougère,

Où monte en pétillant une mousse légère,

Sur les monts du couchant tombe l'astre du jour.

Le peuple se rassemble, il hâte son retour;

II arrive, ô Bacchus! en chantant tes louanges,

Et danse autour du char qui porte les vendanges:

Ce char est couronné de fleurs et de rameaux,

Et la grappe en festons pend au front des taureaux.

Le plaisir turbulent, la joie immodérée,

Les heureux vendangeurs terminent la soirée;

Ils sont tous contents d'eux, du sort et des humains:

Des rivaux réunis un verre arme les mains:

Bacchus a suspendu la haine et la vengeance;

Il fait régner l'amour, il répand l'indulgence.

Deux vieillards attendris se tiennent embrassés;

Tous deux laissent tomber des mots embarrassés;

Dans leurs yeux entr'ouverts brillent d'humides flammes.

Ils font de vains efforts pour épancher leurs âmes;

Et pleins des sentiments qu'ils voudraient exprimer,

Tous deux, en bégayant, se jurent de s'aimer.

Alain, jusqu'à ce jour amant tendre et timide,

Puise dans le nectar une audace intrépide,

Et poursuit Alison qui résiste en fuyant:

Elle hésite, chancelle, et tombe en souriant.

Grégoire à Mathurine allait porter son verre;

Sous ses pas incertains il sent trembler la terre;

Il a vu les lambris et le toit s'ébranler:

La table qu'il embrasse est prête à s'écrouler.

Il tombe, il la renverse, et la cruche brisée

Se disperse en éclats sur la terre arrosée. 
On se lève en tumulte, on part, et les buveurs

Font retentir au loin leurs chants et leurs clameurs;

Ils n'ont point entendu le démon des tempêtes.

Il vient de l'occident, il vole sur leurs têtes,

Et passe en rugissant de vallons en vallons.

Tranquille en ce moment au bruit des aquilons,

Le sage laboureur ne craint plus leurs ravages;

Il a mis ses trésors à couvert des orages;

Des gerbes de Cérès il chargea ses greniers;

Les tonneaux de Bacchus ont rempli ses celliers.

Il a fait plus, déjà la glèbe retournée

Cache sous le sillon l'espoir de l'autre année;

Et même sur les champs, épuisés par leurs dons,

Il déposa l'engrais qui les rendra féconds,

Déjà le riche engrais qui les rendra féconds,

Va ranimer les champs qu'ont épuisés leurs dons. ${ }^{18}$

El texto de Saint-Lambert comprende 91 versos, divididos en siete estrofas, frente a los 24 versos de Thomson y los 208 de que dedicará Meléndez Valdés. Ya en el prólogo o "préliminaire" el autor expone la intención de su imitación, así como lo que lo separa de su modelo; veamos los pasajes más notables:

\section{PRÉLIMINAIRE}

Je présente au jugement du Public un Ouvrage d'un genre dans lequel les François ne se sont pas encore essayés. Plusieurs hommes de lettres et de goût ont pensé que les détails de la Nature et de la vie champêtre ne pouvoient être rendus en vers françois; mais j'avois fait peu de réflexions quand je commençai mon Poème; j'étois jeune, et ce que ces hommes éclairés jugeoient impossible ne me parut pas même difficile...

La Philosophie a pour ainsi dite agrandi et embelli l'univers; on peut le regarder avec plus d'enthousiasme que dans les siècles d'ignorance. Le progrès des sciences comprises sous le nom de Physique, I'Astronomie, la Chymie, la Botanique, etc., ont fait connoître le palais du monde et les hommes qui l'habitent. Depuis que l'homme a trouvé dans la Nature des richesses nouvelles, il a soupçonné qu'il en pouvoit découvrir encore, et il a observé tous les êtres avec une attention curieuse. Des Philosophes éloquents ont rendu la Physique

\footnotetext{
${ }^{18}$ Saint-Lambert: Les Saisons, Poëme. Nouvelle édition. A Londres, M: DCC: LXXXII, pp. 9395. Aclaro que de unas ediciones a otras el autor cambia con frecuencia algunos versos, o a veces estrofas enteras, aunque sin variar prácticamente el poema.

19 Mélanges tirés d'une petite bibliothèque, ou variétés littéraires et philosophiques, par Charles Nodier, Chevalier de la Légion d'Honneur, Bibliothécaire du Roi à l'Arsenal, à Paris, chez Crapelet, imprimeur-éditeur, 1829, pp. 105-106.
}

Hikma 10 (2011), 9-27 
une science agréable; ils en ont répandu les idées, elles sont devenues populaires. Le langage de la Philosophie reçu dans le monde, a pu l'être dans la Poésie; on a pu entreprendre des poëmes qui demandent une connoissance variée de la Nature, et leurs auteurs ont pu espérer des Lecteurs. Les Anglais et les Allemands ont créé le gente de la Poésie descriptive; les Anciens aimoient et chantoient la campagne; nous admirons et nous chantons la Nature.

Ce gente nouveau a sa poétique qui n'est pas fort étendue; il a sans doute ses règles, ses principes; je ne prétends pas les donner, mais qu'il me soit permis de faite quelques réflexions. La Poésie descriptive doit, comme toutes les autres, se proposer d'émouvoir et de graver dans le cœur et la mémoire des hommes, des vérités et des sentiments utiles ou agréables.

Le spectacle de la Nature peur donner différentes émotions.

Elle est sublime dans l'immensité des cieux et des mers, dans les vastes déserts, dans l'espace, dans les ténèbres, dans sa force et sa fécondité sans bornes, et dans la multitude infinie des êtres. Elle est sublime dans les grands phénomènes, comme les tremblements de terre, les volcans, les débordements, les tempêtes. Elle est sublime, dés qu'elle peur donner des sensations qui excitent en nous l'étonnement et la crainte.

Elle est grande et belle, lorsqu'elle nous présente un espace étendu, mais que l'imagination peur terminer, de riches plaines, de belles montagnes, un pays varié, cultivé, peuplé, qui nous promet des biens, la sécurité et le bonheur. Elle est grande et belle, lorsqu'elle nous, donne des sensations qui excitent l'admiration et l'amour...

Vous rendrez la Nature intéressante, si vous la peignez toujours dans ses rapports avec les êtres sensibles; vous la rendrez intéressante, si dans vos descriptions vous répandez quelques vérités de physique et de morale, quelques idées qui éclairent les hommes, des principes d'économie, des sentiments honnêtes: vous la rendrez intéressante, si vous ne la peignez jamais sans être rempli vous même du sentiment qu'elle doit inspirer comme sublime, grande, triste, pauvre, riche, agréable ou belle...

II n'y faut pas placer de malheureux paysans; ils n'intéressent que par leurs malheurs; ils n'ont pas plus de sentiments que d'idées; leurs mœurs ne font pas pures; la nécessité les force à tromper: ils ont cette fourberie, cette finesse outrée, que la nature donne aux animaux foibles et qu'elle a pourvus de foibles armes; parlez d'eux, mais ne les mettez que rarement en action, et surtout parlez pour eux...

Le sujet de ce Poëme est sans doute intéressant; mais pour en augmenter l'intérêt, il a fallu peindre les états de l'homme dans les différentes Saisons: il a fallu observer l'homme dans ses rapports avec la Nature...

Thomson, dans chacun de ses Chants, voit la Nature sublime et grande; il aime mieux la peindre étonnante qu'aimable: peut-être cela est-il plus aisé. Quand on peint les grands phénomènes de la Nature 
sublime, tous les mots font poétiques et il ne s'en présente pas d'autres : quand le tableau ne serait pas achevé, il auroit encore de l'effet. II est plus difficile d'ennoblit les objets communs que de peindre les grands objets et d'animer un paysage que de décrite de belles horreurs.

Thomson n'étoit pas obligé de ramener souvent son Lecteur au but moral que je me fuis proposé; il chantoit la Nature chez un peuple qui la connoît et qui l'aime, et je l'ai chantée chez une nation qui l'ignore ou la regarde avec indifférence. Le poète anglais parle à des amants de leur maitresse: il est sûr de leur plaire. Je veux inspirer de l'amour pour une belle femme qu'on n'a pas vue, et je montre son portrait. Thomson veut qu'on admire la Nature, et je voudrois la faire aimer. ${ }^{19}$

Su obra, que gozó durante décadas de una fama y gloria totales, en el momento del triunfo del Romanticismo en Francia pasará no ya a un segundo lugar, sino a una relegación absoluta como podemos apreciar por el siguiente juicio de Charles Nodier, bibliotecario del Arsenal (uno de los cenáculos del movimiento romántico) al comentar los libros de su biblioteca:

Les SAISONS, poëme, (par Saint-Lambert.) A Amsterdam, (Paris), 1773, in-12.

Je vois à ce seul titre s'indigner justement le bibliophile délicat, qui ne souffriroit pas qu'un volume intrus deshonorât sa collection par un honteux voisinage. Les Saisons de Saint-Lambert! s'écrie-t-il. Et quand ce seroit la plus élégante de toutes les éditions de Didot, avec le luxe déplacé des images et du vélin, que pourroit-on dire d'un pareil ouvrage? Rien de fort piquant, j'en conviens; ce qu'on ne lit plus ne vaut pas la peine d'être critiqué, et sous le rapport de la curiosité, l'exemplaire le plus richement orné de ce livre, ne sera jamais qu'un médiocre bijou. Aussi n'est-ce point en considération de son mérite propre, ou de celui de cette édition, qui est la plus mauvaise de toutes, ou du luxe de quelques accessoires précieux dont le caprice l'auroit enrichi, qu'il figure avec honneur dans mes tablettes auprès d'André Chénier, le seul poète du dix-huitième siècle dont l'impression récente et la tournure à la mode fassent disparate à leurs vénérables vieilleries ${ }^{20}$.

\section{LA IMITACIÓN DE MELÉNDEZ VALDÉS}

El poema de Meléndez, "Las vendimias" es el romance $\mathrm{n}^{\circ} 38$ y consta de 208 versos octosílabos en los que el autor describe el comienzo de la vendimia:

\footnotetext{
19 Saint-Lambert: Les Saisons, Poëme. Nouvelle édition. A Londres, M: DCC: LXXXII, pp. 5-24.

${ }^{20}$ Mélanges tirés d'une petite bibliothèque, ou variétés littéraires et philosophiques; par Charles Nodier, Chevalier de la Légion d'Honneur, Bibliothécaire du Roi à l'Arsenal, Paris, chez Crapelet, imprimeur-éditeur, 1829.
} 
YA dió alegre el fresco otoño,

La señal de la vendimia,

Y su voz redobla el eco

Por los valles y colinas.

Luego descripción de las vides, las labores de preparación, el corte de los racimos, la alegría de los vendimiadores (opuesta a la triste vida de las ciudades) y los devaneos amorosos de mozos y mozas, la maceración de la uva y la cata de los primeros mostos, incluyendo todo hasta el verso 160:

Así triunfa el dios del vino,

Así su inmortal bebida

Borra los cuidados tristes,

Los ánimos regocija.

De ahí en adelante el poeta describe la caída de la noche y las danzas de los vendimiadores a la lumbre:

En tanto del negro ocaso

Desciende la noche umbría,

Y su manto de luceros

Tiende á la atónita vista:

Abrese la alegre danza,

Vivo el crótalo repica,

$Y$ el ruidoso tamborino

Un nuevo delirio inspira.

Para terminar con una reflexión que compara campo y ciudad, añorando la vida en de aldea:

Cuando yo estos dulces versos

Cantaba á mi fácil lira,

En el ocio de mi aldea

En gloriosa paz vivía: 200

Fementido luego el hado

Me arrastró á las grandes villas:

Ví la corte, y perdí en ella

Cuanto bien antes tenia.

Y así abrumado de afanes,

Siempre en duelos y agonías,

¿Quién, esclamó, se volviese

A su aldea y sus vendimias! 
Por lo que concierne a la imitación o adaptación (ya que en absoluto se trata de una traducción), se puede afirmar que Meléndez se sirve de la idea de Thomson y sigue un poco más de cerca a Saint-Lambert, aunque la realidad es que su poema sólo se inspira en los otros dos para describir las costumbres de los vendimiadores extremeños. En ningún caso el romance está impregnado de ese matiz patriótico que desprende, tanto el poema de Thomson, como el de su imitador francés:

That, by degrees fermented, and refin'd,

Round the rais'd nations pours the cup of joy; ${ }^{21}$

C'est toi qui des Gaulois enflammais le courage,

Quand ce peuple vainqueur, du haut des Apennins,

Vint sous leurs toits fumants écraser les Romains.

II voulait de tes dons enrichir sa patrie; ${ }^{22}$

El romance del poeta extremeño cierra la trilogía de los oficios campesinos ensalzando la vida en el campo y anatematizando la vida en la ciudad; a ello seguramente contribuiría su carácter melancólico, mucho más acorde con una vida alejada y reflexiva que parece ser añorara durante toda su existencia el poeta, que no pudo esquivar los problemas de una vida comprometida con la administración, aunque ésta le produjera continuas desgracias y sinsabores. Los romances citados no remiten sólo a un estilo concreto, sino que son una mezcla de su etapa anacreóntica (alegría la vida en el campo, escarceos amorosos, bailes y las danzas en ambiente pastoril...), mezcladas con el tono meditativo de su poesía filosófica, que se corresponde con el de la edad de un hombre que ha vivido ya gran parte de su existencia y se complace en observar a las nuevas generaciones, valorando la vida campesina frente a la corrupción y el vicio de la corte, pero sin caer nunca en el lenguaje grosero de otros poetas de su tiempo.

REFERENCIAS BIBLIOGRAFICAS

CAMERON, Margareth C.: L'influence des "Saisons" de Thomson sur la poésie descriptive en France (1759-1810), Paris: Honoré Champion, 1927.

\footnotetext{
21 "El mosto fermentado lento y elaborado,

brinda por las naciones con una alegre copa".

22 "Tú eres el que encendías el ánimo a los galos, cuando este pueblo invicto desde los Apeninos,

vino en humeantes casas a hollar a los romanos.

Deseaba con tus dones enriquecer su patria".
} 